\title{
FRONTEIRAS, MOBILIDADES E DESIGUALDADES: UMA REFLEXÃO SOBRE A ESCOLA DE/NA FRONTEIRA
}

BORDERS, MOBILITIES AND INEQUALITIES: A REFLECTION ON THE SCHOOL OF/AT INTERNATIONAL BORDER

FRONTERAS, MOVILIDADES Y DESIGUALDADES: UNA REFLEXIÓN SOBRE LA ESCUELA DE/ EN LA FRONTERA

\author{
Ana Maria de Vasconcelos Silva* \\ Luciane Pinho de Almeida*
}

\begin{abstract}
RESUMO
As fronteiras são consideradas como zona de tensão e conflitos vivenciados nas relações dialéticas de exclusão/inclusão, espaços de incessante reconstrução identitária e cultural. Nessa perspectiva, compreendendo a educação como um processo social, este estudo tem como objetivo fazer uma reflexão sobre a educação formal no contexto de/na fronteira de Corumbá (Brasil), Puerto Suarez e Puerto Quijarro (Bolívia), com foco nos alunos de origem boliviana que estudam em escolas do lado brasileiro. Trata-se de um estudo teórico com referência empírica, respaldado em projetos de pesquisa e fundamentado na perspectiva da Psicologia histórico-cultural. A metodologia utilizada foi a pesquisa bibliográfica, e os resultados destacam a necessidade de políticas de educação voltadas para o trânsito entre diferenças e territórios identitários, assim como de discussões que passem pelo campo das políticas linguísticas e educacionais para a diversidade.
\end{abstract}

Palavras-chave: Psicologia histórico-cultural. Fronteira. Educação. Escola de fronteira. Desigualdade social.

\section{ABSTRACT}

International borders are considered a zone of tension and conflicts experienced in the dialectical relations of exclusion/inclusion, spaces of incessant identity and cultural reconstruction. From this perspective, considering education as a social process, this study aims to reflect on formal education in the context of/on the border of Corumbá (Brazil), Puerto Suarez and Puerto Quijarro (Bolivia), focusing on students of Bolivian origin who study at schools on the Brazilian side of the border. This is a theoretical study with empirical reference, supported by research projects and based on

\footnotetext{
"Doutoranda do Programa de Pós-Graduação Stricto Sensu em Psicologia (PPGPsi) da Universidade Católica Dom Bosco (UCDB), professora no Campus Pantanal (CPAN) da Universidade Federal de Mato Grosso do Sul (UFMS). E-mail: vasconcelosana659@ gmail.com.

** Professora no PPGPsi da UCDB. E-mail: lpinhoa@hotmail.com.
} 
the perspective of historical-cultural Psychology. The methodology used was literature research, and the results highlight the need for education policies aimed at the transit between identity and territories differences, as well as discussions that go through the field of linguistic and educational policies for diversity.

Keywords: Historical-cultural Psychology. Frontier. Education. Frontier school. Social inequality.

\section{RESUMEN}

Las fronteras son consideradas zonas de tensión y conflictos experimentados en las relaciones dialécticas de exclusión/inclusión, espacios de identidad incesante y reconstrucción cultural. En esa perspectiva, se considera la educación como un proceso social. Este estudio tiene como objetivo hacer una reflexión sobre la educación formal en el contexto de/en la frontera de Corumbá (Brasil), Puerto Suárez y Puerto Quijarro (Bolivia), centrándose en los estudiantes de origen boliviana que estudian en escuelas del lado brasileño de la frontera. Se trata de un estudio teórico con referencia empírica, apoyado en proyectos de investigación que fundamenta sus datos en la perspectiva de la Psicología histórico-cultural. Se utilizó una metodología de investigación bibliográfica y los resultados destacan la necesidad de políticas educativas destinadas al tránsito entre las diferencias y los territorios de identidad, así como las discusiones que atraviesan el campo de las políticas lingüísticas y educativas para la diversidad.

Palabras clave: Psicología histórico-cultural. Frontera. Educación. Escuela fronteriza. Desigualdad social.

\section{INTRODUÇÃO}

$\Lambda \begin{aligned} & \text { região de fronteira, por ser um território rico em diversidade cultural, } \\ & \text { apresenta-se como um campo fecundo para investigaçōes e formaçōes } \\ & \text { teóricas diversas, na busca de compreender sua construção socioterritorial. }\end{aligned}$ As pesquisas sobre fronteiras têm promovido novas formas de conceituá-la, seus tipos, processos que as constroem, as relações entre os povos e a dinâmica do ir e vir. Desse modo, pesquisar questôes que envolvem região de fronteira têm se constituído um desafio aos investigadores de diversas áreas de conhecimento, inclusive a Psicologia.

Este artigo apresenta um estudo sobre as questóes que envolvem as escolas em região de fronteira em contextos de desigualdade social de adolescentes de origem boliviana que estudam nas escolas de fronteira, tendo como recorte geográfico as cidades de Corumbá, Puerto Suarez e Puerto Quijarro, cidades consideradas 
gêmeas, ${ }^{1}$ localizadas na fronteira entre o Brasil (Estado do Mato Grosso do Sul) e a Bolívia (Departamento de Santa Cruz). Em ambos os países, existe educação básica gratuita, porém o fluxo de estudantes para estudo no ensino fundamental e médio somente ocorre no sentido Bolívia-Brasil, ou seja, dá-se porque a educação é vista como de melhor qualidade no Brasil se comparada à educação boliviana, todavia se pode assinalar intensa interação cultural entre ambos os países.

Para analisar os aspectos psicossociais vividos pelos alunos de origem boliviana em um espaço multicultural como a região de fronteira, faz-se necessário ressaltar a importância de trazer a dimensão cultural à noção de identidade. Tal demanda de análise exige referências conceituais e metodológicas que permitam explicar o ser humano e suas implicaçóes com o mundo objetivo, entendendo que é com base nele que se constrói o mundo subjetivo do indivíduo. Dessa forma, recorremos à Psicologia histórico-cultural de Vigotski e seus colaboradores, Leontiev e Luria, para fazer a leitura desse entrelaçamento entre mundo objetivo e subjetivo, uma vez que essa abordagem entende que o desenvolvimento humano é plasmado pelo movimento de apropriação de formas culturais mais elaboradas de atividade. Tendo por compreensão o homem real, ativo e objetivo, o qual constitui sua própria atividade por meio de seu trabalho, essa concepção é fundamentada no materialismo histórico e dialético de Marx.

Para Marx (1978), o trabalho se desdobra em dois movimentos: produção e alienação da vida. Em tal contexto, o homem desenvolve suas capacidades de produção ao objetivá-las. No entanto as necessidades humanas que originam a produção não são originadas na própria produção, pois estas são históricas e provêm das próprias objetivações de trabalho. Somente o homem pode fazer de sua atividade vital o objeto de sua consciência e de sua vontade, realizando-a de maneira reflexiva. Assim, o homem é um ente genérico, um ser social e comunitário, que só pode levar uma vida humana em sua relação com os demais homens. A sociabilidade humana origina-se no trabalho, numa atividade específica e a partir dela, as formas de sociabilidade estão relacionadas com a evolução das forças produtivas (Urt, Silva, \& Almeida, 2017).

Partindo desses pressupostos, este texto está organizado em três eixos. $\mathrm{O}$ primeiro tratou da dimensão cultural relacionada à noção de identidade em seu desenvolvimento teórico-histórico e social; o segundo eixo discutiu a fronteira e a escola; o último eixo, a fronteira, a escola, os contextos e desafios ante as desigualdades existentes.

\footnotetext{
1 Cidades gêmeas correspondem a adensamentos populacionais cortados apenas pela linha de fronteira (terrestre - fronteira seca ou fluvial). Estão situadas aos pares, ao longo do limite internacional de um país, e apresentam uma paisagem específica e uma dinâmica própria em relação à sua localização junto ao limite internacional. São também geradas por intensas trocas culturais, econômicas e sociais entre Estados nacionais assim como por conflitos advindos das diferenças étnicas, culturais e políticas.
} 


\section{CATEGORIA IDENTIDADE E CULTURA}

Para Lopes (2002), acerca da categoria identidade, as transformaçóes sociais advindas do século XVIII verteram num conjunto de novas concepções e conteúdos reflexivos acerca do mundo e da realidade das ciências da época. Assim, "As chamadas ciências naturais não deram conta de responder às indagações surgidas com a constatação, a descrição e as interpretações que, desde o século XVI, se faziam a respeito do homem 'selvagem' ou 'primitivo' do novo mundo" (Lopes, 2002, p. 6). Tais indagações produziram, no século XIX, uma reformulação do conceito de humanidade, o que acarretou um novo delineamento no desenvolvimento da Filosofia, no Ocidente, passando à Filosofia da ação humana, dando origem à Psicologia e à Antropologia. Com essa divisão, buscava-se instituir modelos e limites mais sólidos ao estudo empírico dos registros teóricos que a Filosofia produziu a respeito da condição do homem nos parâmetros culturais em que sua origem humana é ancorada. Ao olhar o homem em seu processo histórico, a reflexão filosófica empreendeu um movimento com dois pressupostos: o sujeito e o tempo (Lopes, 2002). Segundo essa análise de Lopes (2002, p. 7) essa reflexão possibilitou três registros da consciência humana:

Pela identidade consigo mesma - a figura psicológica do "eu", o ego - nesse sentido, o ego é uma entidade: id-entidade. A figura moral ou ética, que se pensa em responsabilidade e liberdade, produziu a consciência da pessoa. Já pela faculdade de síntese ou conhecimento, cultural ou histórico, surgiu o sujeito consciente de sua ação.

Dessa forma, a Psicologia com foco no psicológico do indivíduo encontraria no comportamento as explicações para as ações humanas, e a Antropologia focaria no estudo da noção de pessoa, atendo-se ao conhecimento das sociedades ditas "primitivas" ou tradicionais, entendendo que as noções de indivíduo e de sujeito (histórico) não existiriam ou estariam diluídas nas manifestações coletivas. Nesse sentido, as açôes humanas seriam justificadas pela concepção de condutas e, do mesmo modo, a ação individual, pois esta atenderia à orientação coletiva normativa. Assim, os registros da consciência humana, referentes ao sujeito consciente de sua ação, foram descritos e analisados pela Ciência Política, História e Sociologia, influenciados pelas reflexôes de filósofos como Hegel e Marx, que se dedicaram a estudar o homem na razão de sua história ocidental, inspirada numa ordem de relaçôes temporais definida pela contradição (Lopes, 2002). Para Marx, a concepção de sujeito e contradição adotam suas dimensões humanas e materiais como determinantes, ou seja, a contradição e as condições que a geraram são superadas pela ação do sujeito.

Ao retornar, portanto, à categoria identidade, no que se refere aos registros da consciência que se desdobram nos termos pessoa, sujeito e indivíduo, vale 
ressaltar que a identidade perpassa tais referências, constituindo-se transversal e dialeticamente sob e sobre elas. Assim, em relação às dimensões filosóficas, as concepções de sujeito no seu contexto histórico vão se diferenciando das concepções de indivíduo e de pessoa pela compreensão de sua gênese e do caráter explicativo que tais concepções assumem, dentro da realidade histórica em que são gestadas, sujeitas a reflexões afetadas pelas dinâmicas e ambiguidades engendradas na sincronicidade desses registros na vida social.

Nessa perspectiva, Vigotski e seus colaboradores, Leontiev e Luria, com base na análise e investigação da crise que a Psicologia estava enfrentando no início do século $\mathrm{XX}$, entenderam que a superação desta se daria com a criação de uma Psicologia geral de bases científicas, ancorada no materialismo histórico e dialético e, para isso, teria de redefinir seu objeto e delinear o problema a partir de uma investigação na qual o homem fosse analisado em sua totalidade, em sua mediação com o mundo de contradiçôes, o que significa dizer que todo estudo também não pode esquecer a historicidade. Desse modo, esses autores aprofundaram seus estudos na compreensão dos pressupostos teóricos de Marx e Engels redimensionando-os para a área da Psicologia.

A totalidade concreta é um dos conceitos centrais da dialética materialista, ou seja, a própria realidade na sua estrutura é dialética, fundamenta-se na ideia de que todas as regiōes da realidade objetiva são sistêmicas, exercem entre si uma influência recíproca, constituindo um todo em movimento de autocriação permanente (Kosik, 2011, p. 59).

A dialética não pode entender a totalidade como um todo já feito e formalizado, que determina as partes, porquanto à própria determinação da totalidade pertencem a gênese e o desenvolvimento da totalidade, o que, de um ponto de vista metodológico, comporta a indagação de como nasce a totalidade e quais são as fontes internas do seu desenvolvimento e movimento.

\section{O autor segue explicando que:}

É o homem como sujeito histórico real, que no processo social de produção e reprodução cria a base e a superestrutura, forma a realidade social como totalidade de relaçôes sociais, instituiçôes e ideias; e nesta criação da realidade social objetiva, cria ao mesmo tempo a si próprio, como ser histórico e social, dotados de sentidos e potencialidades humanas, e realiza o infinito processo da humanização do homem (Kosik, 2011, p. 61).

Vigotski (1991) afirma que as características tipicamente humanas se formam ao longo da história e se desenvolvem durante toda a vida de um indivíduo, resultantes da interação dialética do homem e do meio sociocultural. Em outras 
palavras, é a partir da base material do processo histórico-social que se produzem as condições para o humano, pois:

Na produção social da sua vida, os homens contraem determinadas relações necessárias e independentes da sua vontade, relações de produção que correspondem a uma determinada fase de desenvolvimento das suas forças produtivas materiais. O conjunto dessas relaçôes de produção forma a estrutura econômica da sociedade, a base real sobre a qual se levanta a superestrutura jurídica e política e à qual correspondem determinadas formas de consciência social. $\mathrm{O}$ modo de produção da vida material condiciona o processo da vida social, política e espiritual em geral. Não é a consciência do homem que determina o seu ser, mas pelo contrário, o seu ser social é que determina a sua consciência (Engels, 2001, p. 301).

Assim, o trabalho é resgatado como finalidade, conferindo-lhe um caráter prático que se efetiva na relação do homem com a natureza (Marx, 1978). O trabalho assume sua significação universal como mediação na relação entre sujeito e objeto, não somente como chave que abre a possibilidade da compreensão das diferentes determinações inerentes a todas as formas de alienação, mas também como o centro de referências práticas que visa à superação real das mediações historicamente específicas, por meio das quais a base ontológica da existência humana é alienada na sociedade capitalista (Marx, 1984).

Em tal contexto, para compreender o sujeito, é preciso pô-lo em relação com o mundo do qual participa. A obra de Vigotski deixa claro que "A constituição concreta dos sujeitos só se dá em relação com as condições objetivas dadas e, no caso, num mundo em que as relaçôes sociais se pautam nas relações de troca suscitadas pela lógica da mercadoria" (Facci, Barroco, \& Leonardo, 2009, p. 126).

Nessa perspectiva, as fronteiras são espaços de incessante reconstrução identitária e cultural, apresentando um dinamismo próprio. As fronteiras políticas são criações humanas, delimitadas e demarcadas por processos de ocupação militar, demográfica, econômica, política e cultural nos territórios nacionais e, de acordo com Albuquerque (2009), apresentam variados sentidos e significados construídos pelas populações que convivem em seu cotidiano com as travessias e os controles estatais. 


\section{A FRONTEIRA BRASIL X BOLÍVIA}

Etimologicamente, o termo fronteira está pautado em conquista territorial e estabelecimento de limites relacionados ao âmbito militar, estabelecendo a delimitação entre dois territórios. Albuquerque (2010) pondera que é no contexto da Europa moderna que se dá a divisão do mundo em Estados territoriais, e, nesse sentido, o termo fronteira vincula-se aos limites políticos dos Estados nacionais. Desse modo, a fronteira, a partir da formação e expansão do Estado-nação, passa a ser sinônimo de limite de soberania, ou seja, a linha de fronteira representa os limites internacionais. Mas é importante destacar que as noçôes de fronteira e limite foram modificando-se historicamente, reposicionando a abordagem da fronteira de uma concepção linear para uma concepção de área ou região de fronteira, como explica Machado (2006, p. 61):

$\mathrm{O}$ conceito de fronteira internacional se refere a uma área indefinida, uma zona_percorrida pelo limite internacional e que se aproxima da noção geográfica de regiāo. No entanto, do jeito que as coisas são, o ambiente geográfico de fronteira é mais complexo do que aquele simbolizado pelo limite, pois se faz pela territorialização de grupos humanos e de redes de circulação e intercâmbio, unidos pela permeabilidade dos limites estatais através da comunicação entre populaçôes pertencentes a diferentes sistemas de poder territorial. Não se confunde, portanto, com a permeabilidade dos limites estatais atribuída à Internet e aos fluxos mundiais de capital (abstrato). É a posição geográfica singular, de começo e fim do estado nacional, que confere a fronteira uma territorialização definida pela proximidade entre populações formalmente separadas pelo limite internacional. A noção de zona de fronteira, neste caso, se refere a um espaço relacional e não dicotômico. Nesse sentido de espaço relacional não é um paradoxo que a zona de fronteira seja ao mesmo tempo lugar de comunicação e troca, e lugar de tensão e conflito. O que nos parece interessante neste último caso é que as partes em litígio podem fazer valer o limite internacional em oposição à fronteira como lugar de comunicação e de mobilidade transfronteiriça (grifos nossos).

Conforme analisa Machado (2005), as fronteiras internacionais apresentam um contexto complexo para desenvolver políticas públicas, por envolver interesses, elementos espaciais e legislação de países distintos, assim como designa uma forma encontrada para tratar dos fluxos de bens, capitais e pessoas que caracterizam esses espaços. Portanto a zona de fronteira é definida pelas faixas de cada lado do limite internacional e caracteriza-se por interaçôes que, embora internacionais, criam um meio geográfico próprio de fronteiras que apenas pode ser compreendido na escala local/regional. Ao se pensar na escala local/regional, as cidades gêmeas constituem o meio geográfico que melhor caracteriza a zona de fronteira. Assim, Machado (2005, p. 261) explica:

Estes adensamentos populacionais, cortados pela linha de fronteira, seja seca ou fluvial, articulada ou não por obra de infraestrutura, apresentam grande potencial de integração 
econômica e cultural assim como manifestaçōes localizadas dos problemas característicos da fronteira. Aí adquirem maior densidade, com efeitos diretos sobre o desenvolvimento regional e a cidadania, por esses motivos é que as cidades gêmeas devem constituir-se em um dos alvos prioritários das políticas públicas para a zona de fronteira. A concentração de efeitos territoriais nas cidades gêmeas (incluindo fatores de produção - terra, trabalho, capital e serviços públicos e privados) e a extensão desses efeitos numa distância determinada rumo ao interior de cada território nacional têm implicações práticas para a atuação do estado em suas respectivas faixas de fronteira.

Assim, a fronteira internacional é engendrada como parte das relaçóes humanas, em suas mais variadas formas, sejam elas políticas, econômicas, sociais, étnicas, religiosas, culturais ou simbólicas. Assim, a fronteira é vista como um lugar com simbolismos estabelecidos a partir dos contatos entre os sujeitos, as línguas e as culturas (Becker, 2007).

O Brasil faz divisa com quase todos os países da América do Sul, com exceção de Chile e Equador. Tem cerca de $23.086 \mathrm{~km}$ de fronteira, com $7.367 \mathrm{~km}$ de fronteiras marítimas e $15.719 \mathrm{~km}$ com os países do continente sul-americano. É o quinto maior país do mundo em extensão territorial e o maior da América do Sul (Torchi, \& Silva, 2014). Por sua vez, o Estado de Mato Grosso do Sul faz fronteira com dois países sul-americanos, Bolívia e Paraguai, e é composto por 79 municípios, sendo 3 na linha de fronteira (Amambaí, Aral Moreira e Coronel Sapucaia) e 5 são cidades-gêmeas (Bela Vista, Mundo Novo, Paranhos, Ponta Porã e Corumbá) (Torchi, \& Silva, 2014).

O Município de Corumbá encontra-se localizado no oeste do Estado de Mato Grosso do Sul, na fronteira do Brasil com a Bolívia. Limita-se territorialmente, a leste, com Ladário-MS, pelo lado brasileiro, e, a oeste, com Arroyo Concepción, Distrito de Puerto Quijarro, da Província Germán Busch, Departamento de Santa Cruz, no lado oriental boliviano. Essas localidades são caracterizadas como cidades gêmeas, já que, mesmo mantendo os limites físicos, partilham serviços e ações, tais como educação, saúde, lazer e comércio, e desenvolvem intensas trocas de serviços e ações transnacionais, como empresas sediadas num lado da fronteira, mas que retiram matéria-prima no país vizinho (Brasil, 2005). Destacase aqui a interdependência entre brasileiros e bolivianos pelo distanciamento geográfico entre os principais centros urbanos, já que as cidades de Corumbá e Ladário estão distantes da capital, Campo Grande, cerca de 420 km; e Puerto Quijarro e Puerto Suarez, distantes em mais de $600 \mathrm{~km}$ do grande centro urbano Santa Cruz de La Sierra.

Costa (2015) pontua que a nacionalidade constitui uma categoria central na vida dos moradores fronteiriços, "que organiza o espaço cotidiano, determina o acesso a direitos ou define a situação de estrangeiros, e é condição para tornar-se 
pessoa na vida local" (Grimson, 2003 apud Costa, 2015, p. 38). O autor ainda chama a atenção para a questão da identidade na fronteira Brasil-Bolívia, pois esta pode ser problematizada não apenas por

Critérios de nacionalidade (brasileiros/bolivianos), mas também por critérios étnicos (índios/não índios). Há uma dupla alteridade do boliviano em solo brasileiro: ao mesmo tempo em que é visto como um "outro" nacional (estrangeiro) é também representado como um "outro" (indígena), duplicando, em grande medida, o estigma social que recai sobre o grupo (Costa 2015, p. 38).

É nesse sentido que este artigo discute a desigualdade social na escola fronteiriça.

\section{DESIGUALDADE SOCIAL, ESCOLA E FRONTEIRA EM CORUMBÁ-MS}

O tema diversidade na área das políticas educacionais é recente. Surge a partir da Constituição de 1988 e da implantação da Lei no 9.394/1996 (Lei de Diretrizes e Bases da Educação Nacional - LDB). Com a Constituinte de 1988, retoma-se a participação de diversos grupos organizados da sociedade, como os movimentos sociais, nas conjecturas das políticas públicas. Assim, a Constituição é considerada um avanço no sentido de assegurar direitos sociais, entre eles o acesso à educação. Waldman (2012) pontua que a Constituição apresenta, pela primeira vez, o princípio da dignidade da pessoa humana como fundamental e destaca como objetivos fundamentais, a "promoção do bem para todos, sem preconceitos de origem, raça, sexo, cor, idade e quaisquer outras formas de discriminação" (Waldman, 2012, p. 63).

Por sua vez, a Lei de Diretrizes e Bases da Educação Nacional de 1996, com base na Constituição Federal, também avança. Em 2003, inclui-se a Lei 10.639/2003, que torna obrigatório no currículo das escolas públicas brasileiras o ensino de História da África e da Cultura Afro-brasileira. Outro dispositivo que busca abordar a diversidade étnico-racial nas escolas brasileiras são os Parâmetros Curriculares Nacionais, que contemplam a pluralidade cultural como tema transversal (Lei 10.639/2003).

Barth (2000 apud Costa, 2015) explicita que o que define os grupos étnicos e explica sua persistência são os processos de exclusão e inclusão, e não o conteúdo cultural. A identidade étnica é construída e transformada na interação entre os grupos sociais, contribuindo para organizar, inclusive, o teor dessas interaçôes. 
Neste sentido, Costa (2015) aponta o fato de muitos indivíduos de origem boliviana serem nascidos em Corumbá, terem documentos de identidade brasileiros, estudarem nas escolas brasileiras, prestarem o serviço militar obrigatório, serem bilíngues em sua maioria, demonstrando a situação intersticial de suas identidades. Mesmo assim, continuam sendo chamados de bolivianos pelos brasileiros. Muitos desses atores sociais moram no lado boliviano da fronteira e mantêm os laços culturais e identitários com a Bolívia, identificandose, portanto, como bolivianos e não como brasileiros (mesmo que nascidos no Brasil). Desse modo, Moraes (2012) explicita:

Cabe ressaltar que todas as crianças na linha de fronteira que ali estudam são oficialmente brasileiras, já que documentadas com registro de nascimento no Brasil. Outro fato importante a pontuar é corrigir aquilo que foi estereotipado nesses alunos, até mesmo por pesquisadores: bolivianos que estudam no Brasil. Uma vez que todos, ou a maioria deles, são documentados, com registro de nascimento no Brasil o qual thes garantem a nacionalidade brasileira. Assim, muitos estudantes chamados bolivianos, na verdade, pelo documento, são brasileiros residentes na Bolívia. Essa é a realidade das duas escolas de Corumbá que mais recebem alunos moradores da Bolívia: CAIC e Eutrópia Gomes Pedroso. Nela todos os alunos moradores da Bolívia possuem certidão de nascimento brasileira, embora seus pais sejam bolivianos. Nessa escola estudam irmãos, primos, conhecidos, formando uma rede de mútua ajuda (p. 13).

Em tal contexto, Moraes (2012) e Ribeiro (2011) ressaltam que as escolas situadas em regiōes de fronteira, especificamente em Corumbá, reproduzem os códigos hegemônicos dos centros de poder. Nesse sentido, é importante observar que a escola da fronteira não se diferencia das demais escolas públicas brasileiras, uma vez que as disciplinas oferecidas são as sugeridas pelo Conselho Estadual ou Municipal de Educação e os livros didáticos usados são aqueles enviados pelo Ministério da Educação (MEC), os quais não consideram as necessidades locais. Ribeiro (2011) retoma as ideias de Cavalcante (2004, p. 63) e relembra que "As peculiaridades da fronteira e as possibilidades de ensino que elas trazem são ignoradas na maioria das escolas do Brasil. As aulas são dadas como em qualquer outro lugar do país". Assim, é inegável o processo de discriminação sofrido pelos alunos de origem boliviana, camadas segregadas se tornam invisíveis para a sociedade (Costa, 2008; Gentile, 2003) e, ou, são percebidas como inferiores e como objetos de temor.

Essas e outras situações de caráter preconceituoso com os fronteiriços, especialmente com os bolivianos que vivem nessa região, lançam evidências de entraves étnicos na fronteira Brasil-Bolívia, assinalando para os múltiplos desafios discriminatórios e de desigualdade social em relação aos que convivem nessa fronteira e, relativamente, na escola. 
Nesse ponto, é importante destacar que a desigualdade social é um fenômeno histórico e se manifesta de várias formas (classe, étnica, racial, sexo etc.); "São diferenças hierárquicas evitáveis e moralmente injustificadas. A desigualdade é uma violação aos direitos humanos" (Therborn, 2010, p. 2). No caso brasileiro, a desigualdade aparece atrelada à cultura da exclusão, que também é identificada na organização e na estrutura do nosso sistema escolar. Cultura essa que "legitima práticas, rotula fracassados, trabalha com preconceitos de raça, gênero e classe, e que exclui”" (Arroyo, 2000, p. 12). Na concepção liberal, não se trata de preconizar uma sociedade na qual desaparecerão as desigualdades; trata-se de justificá-las no âmbito da desigualdade de oportunidades. No nível das ideias, a desigualdade social, inerente ao capitalismo, dá-se pela tradução das desigualdades sociais em desigualdades raciais, étnicas, pessoais e culturais.

Vigotski, envolvido com as questões educacionais do período em que viveu, buscou desenvolver uma Psicologia que tanto fosse cientificamente rigorosa quanto útil para a mudança social progressiva. $\mathrm{O}$ autor alertava que:

Em todas as épocas, independentemente de sua denominação e qualquer que fora a sua ideologia, toda educação tem sido sempre uma função do regime social, no sentido de que, ao fim e ao cabo, o fator decisivo para o estabelecimento de novas reações na criança vinha dado pelas condições que tinham sua origem no meio ou, mais amplamente, nas interrelaçôes entre o organismo e o meio (Vigotski, 1991, p. 59).

Em tal contexto, a escola determina "todo o destino do desenvolvimento intelectual da criança, inclusive do desenvolvimento dos seus conceitos". Conforme menciona o autor, os conceitos científicos "não podem surgir na cabeça da criança senão a partir de tipos de generalização elementares e inferiores preexistentes, nunca podendo inserir-se de fora da consciência da criança (Vigotski, 2001 p. 262).

Portanto, apesar dos avanços nas políticas educacionais para a diversidade já mencionados, Ataíde e Moraes (2003, p. 83) mencionam a tendência de homogeneização curricular que isola a escola de seu contexto. O Brasil, como um todo, "Produz um projeto pedagógico exógeno e xenófobo". Nesse sentido, Santomé (1993) ressalta o silenciamento existente nos currículos nacionais em relação às minorias no espaço escolar e argumenta que, no caso da presença de migrantes nas escolas fronteiriças, tem-se a impressão de sua inexistência.

No que se refere à educação na fronteira, o Ministério da Educação do Brasil, no âmbito das discussões do Mercosul (Mercado Comum do Sul), em parceria com os ministérios de Educação dos países que fazem fronteira com o Brasil (Argentina, Bolívia, Paraguai, Uruguai, Venezuela, Colômbia, Peru, Guiana e 
Guiana Francesa), realiza, desde 2005, o Programa Escolas Interculturais de Fronteira (PEIF), com o objetivo de proporcionar o desenvolvimento educacional e social da região fronteiriça (Assis, 2016).

Conforme as autoras Barreda, Gomes e Marcondes (2014), o Programa de Escolas Interculturais de Fronteira, da Universidade Federal de Mato Grosso do Sul (PEIF/UFMS), em Corumbá-Puerto Quijarro/Puerto Suárez, foi concebido processualmente e por necessidade de se estabelecer um diálogo entre os atores dos sistemas educativos brasileiro e boliviano. A UFMS, em parceria com a Secretaria Municipal de Educação de Corumbá e a Dirección Distrital de Educación de Puerto Quijarro, organizaram o primeiro curso de formação continuada para professores bolivianos e brasileiros, com foco nos temas educação e metodologia de projetos, interculturalidade e línguas que circulam nessa fronteira. Participaram do PEIF/UFMS, no período de 2010 a 2015, 3 escolas de Corumbá e 10 da Bolívia. O projeto consiste em encontros periódicos com os professores dos dois países, para estudos e trocas de experiências. O PEIF tem como base a interculturalidade entre os países participantes, a interação linguística e o próprio método de atuação, que é a pedagogia de projetos.

O estudo das autoras Flandoli e Bilange (2016), intitulada "Quem e como são os que habitam o outro país desta fronteira? Bolívia e bolivianos sob o olhar de alunos do ensino fundamental: Corumbá-MS”, surge de suas experiências como professoras e tutoras do PEIF. A pesquisa apresenta dados que configuram o desenho social da Bolívia e dos bolivianos nos textos dos alunos do $6^{\circ}$ e do $7^{\circ}$ ano do ensino fundamental II, da Escola Municipal de Educação Integral Luiz Feitosa Rodrigues, os quais foram instados a escrever sobre a fronteira e sobre a Bolívia. As autoras concluem:

Observa-se a percepção da diferença como diversidade, mas fundamentalmente os textos são marcantes pela noção da diferença, imprimindo ao brasileiro certa superioridade cultural sobre o boliviano, fato que, a nosso entender, deve ser observado nas nossas escolas de fronteira, pois, segundo Torres Santomé (2011, p. 213), os estabelecimentos de ensino "são um elemento a mais na produção e reprodução de discursos discriminatórios", por isso o olhar diferenciado e atento sobre tais representações nesse ambiente é premente e necessário (Flandoli \& Bilange, 2016, p. 118).

A percepção de suposta superioridade cultural dos brasileiros em relação aos bolivianos, apontada pela pesquisa citada, foi observada também na pesquisa de Bumlai e Bilange (2014), realizada em duas escolas da fronteira Bolívia-Brasil, Puerto-Quijarro-Corumbá, com o objetivo de realizar diagnóstico cultural e sociolinguístico para o PEIF a fim de entender o encontro das múltiplas culturas que fazem parte do ambiente escolar dessa fronteira. 
De acordo as autoras citadas, a pesquisa apontou que os estudantes observados na Bolívia têm dificuldade com a língua portuguesa na fala e dificuldade na escrita, além de um conflito de identidade em relação à fronteira, por ser uma região estigmatizada. No que diz respeito à representação social dos brasileiros em relação aos bolivianos, a pesquisa demonstrou que esses são vistos por parte dos brasileiros como "sujos", entre outras denominações preconceituosas.

Nessa perspectiva, Sawaia (2001, p. 104) esclarece que:

O sofrimento ético-político abrange as múltiplas afecções do corpo e da alma que mutilam a vida de diferentes formas. Qualifica-se pela maneira como sou tratada e trato o outro na intersubjetividade, face a face ou anônima, cuja dinâmica, conteúdo e qualidade são determinados pela organização social. Portanto, o sofrimento ético-político retrata a vivência cotidiana das questôes sociais dominantes em cada época histórica, especialmente a dor que surge da situação social de ser tratado como inferior, subalterno, sem valor, apêndice inútil da sociedade. Ele revela a tonalidade ética da vivência cotidiana da desigualdade social, $\mathrm{da}$ negação imposta socialmente às possibilidades da maioria apropriar-se da produção material, cultural e social de sua época, de se movimentar no espaço público e de expressar desejo e afeto.

Araujo, Conceição e Carvalho (2015) argumentam que as escolas de fronteira são espaços conflituosos e hierárquicos nos quais se manifesta a "arrogância" dos alunos brasileiros em relação aos alunos de origem boliviana, e esse espaço revela, em discursos políticos e estatais, apenas na aparência, a possibilidade de integração entre esses dois povos.

Para Sawaia (2001), conhecer o sofrimento ético-político é pesquisar as formas sutis de espoliação humana por trás da aparência da integração social. Isso significa "entender a exclusão e a inclusão como as duas faces modernas de velhos e dramáticos problemas - a desigualdade social, a injustiça e a exploração" (Sawaia, 2001, p. 104). A autora enfatiza que faz a opção pela expressão dialética exclusão/inclusão para marcar que ambas "Não constituem categorias em si, cujo significado é dado por qualidades específicas invariantes, contidas em cada um dos termos, mas que são da mesma substância e formam um par indissociável, que se constitui na própria relação". A dinâmica entre elas demonstra a capacidade de uma sociedade existir como um sistema (Sawaia 2001, p. 108).

Assim, pesquisadores que se dedicam a analisar a presença dos alunos de origem boliviana nas escolas públicas de Corumbá (Bumlai, \& Bilange, 2014; Costa, Silva, \& Souza, 2010; Flandoli, \& Bilange, 2016; Silva \& Souza, 2012) têm apontado para as lacunas e contradições existentes no atendimento a essa população e à realidade da fronteira, sendo importante e necessário que se façam mais estudos sobre a questão. Isso para que sejam cada vez mais intensificados os 
enfrentamentos quanto à discriminação e às desigualdades existentes nas escolas, discutindo com os alunos da fronteira o valor regional e o reconhecimento de que o "outro" não é o "estrangeiro", mas sim aquele com quem se divide um território e aspectos culturais, formando assim uma só identidade.

\section{CONSIDERAÇÕES FINAIS}

É preciso um olhar crítico para impulsionar a consciência do papel político que exercem as instituições escolares, propondo a desnaturalização das desigualdades sociais e educacionais, contribuindo, assim, com a constituição de sujeitos mais conscientes e autônomos. Ampliar as discussões sobre uma educação comprometida com a emancipação humana se faz necessário.

$\mathrm{Na}$ perspectiva da educação como um direito humano, ela é concebida como um direito universal e inteiramente relacionado à dignidade humana, ou seja, direito de todos, sem distinção de qualquer natureza, seja ela social, econômica, cultural, de gênero ou étnico-racial. Assim, em área de fronteira, as crianças e adolescentes devem ter o direito à escolarização, sem impedimento por sua nacionalidade. As pesquisas realizadas em escolas da fronteira de Corumbá (Brasil), Puerto Suarez e Puerto Quijarro (Bolívia), focos deste artigo, apontam para a necessidade de discussóes que passem pelo campo das políticas linguísticas e educacionais para a diversidade. 


\section{REFERÊNCIAS}

Albuquerque, J. L. (2009). A dinâmica das fronteiras: deslocamento e circulação dos "brasiguaios" entre os limites nacionais. Horizontes Antropológicos, 15 (31), 137-166.

Albuquerque, J. L. C. (2010). A dinâmica das fronteiras: os brasiguaios na fronteira entre o Brasil e o Paraguai. São Paulo: Annablume/FAPESP.

Araujo, A. P., Conceição, O., \& Carvalho, L. C. (2015). A arrogância revelada no conflito: bolivianos e brasileiros no espaço escolar da cidade de Corumbál MS. Espaço Aberto, 5 (1), 145-162.

Arroyo, M. G. (2000). Fracasso-sucesso: um pesadelo que perturba nossos sonhos. Em Aberto, 17 (71), 33-40.

Assis, J. H. V. P. (2016). Veias abertas nas fronteiras internacionais do Brasil: percalços na efetivação da educação como um direito universal. International Studieson Law and Education, 22, 83-94.

Ataíde, Y. D. B., \& Morais E. S. (2003). A (re)construção da identidade étnica afrodescendente a partir de uma proposta alternativa de educação pluricultural. Revista da FAEEBA - Educação e Contemporaneidade, 12 (19), 81-98.

Barreda, S. V. M., Gomes, M. R., \& Marcondes, M. L. (2014). Relato de experiência no Peif: o turismo como resgate identitário na fronteira CorumbáPuerto Quijarro. Revista GeoPantanal, 17, 107-124.

Becker, B. K. (2007). Amazônia: geopolítica na virada do II milênio. Rio de Janeiro: Garamond.

Brasil. (1998). Ministério da Educação. Parâmetros curriculares nacionais: pluralidade cultural. Brasília: MEC/SEF.

Brasil. (2005). Ministério da Integração Nacional. Secretaria de Programas Regionais. Programa de Desenvolvimento da Faixa de Fronteira. Proposta de Reestruturação do Programa de Desenvolvimento da Faixa de Fronteira. Brasília: Ministério da Integração Nacional.

Bumlai, D. U. M., \& Bilange, E. M. A. (2014). Encontro intercultural em escolas da fronteira Brasil-Bolívia: diagnóstico para melhor integração. Revista GeoPantanal, 17, 47-57. 
Cavalcante, M. L. (2005, dezembro). Escolas de fronteira: onde se trocam cultura, idioma e conhecimento. Revista Nova Escola, 178.

Constituição da República Federativa do Brasil (1988). (1988). Brasília: Portal da Legislação. Recuperado a partir de http://www.planalto.gov.br/ccivil_03/ constituicao/constituicao.htm.

Costa, F. B. (2008). Moisés e Nilce: retratos biográficos de dois garis: um estudo de Psicologia social a partir de observação participante e entrevistas. (Tese de Doutorado), Instituto de Psicologia, Universidade de São Paulo, São Paulo.

Costa, G. V. L. (2015). Os bolivianos em Corumbá-MS. Mana, 21 (1), 35-63.

Costa, V. C., Silva, A. S., \& Souza, T. F. P. B. (2010). A inclusão de crianças bolivianas nas escolas municipais de Corumbá-MS. (Relatório Final de Iniciação Científica), CPAN, Universidade Federal do Mato Grosso do Sul, Campo Grande.

Engels, F. (2001). Sobre o papel do trabalho na transformação do macaco em homem. In K. Marx, \& F. Engels. Obras escolhidas: Marx \& Engels. (Vol. 2, pp. 257-280). (11a ed.). São Paulo: Alfa-Ômega.

Facci, M. G. D., Barroco, S. M. S., \& Leonardo, N. S. T. (2009). A historicidade na constituição do sujeito: considerações do marxismo e da Psicologia históricocultural. In E. Tomanik, A. M. P. Caniato, \& M. G. D. Facci, M. G. D. (Org.), A constituição do sujeito e a historicidade. (pp. 107-131). Campinas: Alínea.

Flandoli, B. R. G. X., \& Bilange, E. M. A. (2016). Quem e como são os que habitam o outro país desta fronteira? Bolívia e bolivianos sob o olhar de alunos do ensino fundamental: Corumbá-MS. Intermeio, 21/22 (42/44),105-120.

Gentili, P. (2003). Educar na esperança em tempos de desencanto. Petrópolis: Vozes.

Kosik, K. (2011). Dialética do concreto. C. Neves, \& A. Toríbio (Trad.). (2a ed.). Rio de Janeiro: Paz e Terra.

Lei no 9.394, de 20 de dezembro de 1996. (1996, 20 dezembro). Estabelece as diretrizes e bases da educação nacional. Brasília: Portal da Legislação. Recuperado a partir de http://www.planalto.gov.br/ccivil_03/leis/L9394.htm

Lei no 10.639, de 9 de janeiro de 2003. (2003, 9 janeiro). Altera a Lei no 9.394, de 20 de dezembro de 1996, estabelece as diretrizes e bases da educação nacional, para incluir no currículo oficial da Rede de Ensino a obrigatoriedade 
da temática "História e Cultura Afro-Brasileira", e dá outras providências. Brasília: Portal da Legislação. Recuperado a partir de http://www.planalto.gov. br/ccivil_03/leis/2003/L10.639.htm

Lopes, J. R. (2002). Os caminhos da identidade nas Ciências Sociais e suas metamorfoses na Psicologia social. Psicologia \& Sociedade, 14 (1), 7-27.

Machado, L. O. (2005). Estado, territorialidade, redes: cidades-gêmeas na zona de fronteira sul-americana. In M. L. Silveira (Org.), Continente em chamas: globalização e território na América Latina. (pp. 243-284). Rio de Janeiro: Civilização Brasileira.

Machado, L. O. (2006). Cidades na Fronteira Internacional: conceitos e tipologia. In Anais, 2 Conferência Internacional de Desenvolvimento Urbano em Cidades de Fronteira (pp. 58-69). Foz de Iguaçu: IAB.

Marx, K. (1978). Para a crítica da economia política. São Paulo: Abril Cultural. (Coleção Os Pensadores).

Marx, K. (1984). Manuscritos, economia y filosofia. Madrid: Alianza.

Moraes, L. M. (2012). Bilinguismo e jogo de identidades na regiāo de fronteira: a escola Eutrópia Gomes Pedroso de Corumbá. (Dissertação de Mestrado), Universidade Federal do Mato Grosso do Sul, Campo Grande.

Ribeiro, M. L. O. (2011). O idioma e a escola de fronteira como fatores de inclusão social de crianças e adolescentes em Corumbá (BR) e Puerto Quijarro (BO). (Dissertação de Mestrado), Universidade Federal do Mato Grosso do Sul, Campo Grande.

Santomé, J. T. (1993). Las culturas negadas y silenciadas en el currículum. Cuadernos de Pedagogía, 217, 60-66. Recuperado a partir de http://jurjotorres. $\mathrm{com} /$ ? $\mathrm{p}=3568$

Sawaia, B. (2001). O sofrimento ético-político como categoria de análise da dialética exclusão/inclusão. In B. Sawaia (Org.), As artimanhas da exclusão social: análise psicossocial e ética da desigualdade social. (pp. 97-118). Petrópolis: Vozes.

Silva, A. S., \& Souza, T. F. P. B. (2012). Crianças bolivianas na educação infantil brasileira. Textos \& Debates, 21, 23-36.

Therborn, G. (2010). Os campos de exterminio da desigualdade. São Paulo: Novos Estudos. 
Torchi, G. F. C., \& Silva, C. P. A. (2014). Expansão do Programa Escolas Interculturais de Fronteira no Estado de Mato Grosso do Sul. Dossiê Escolas Interculturais de Fronteira. Revista GeoPantanal, 17, 33-46.

Urt, S., Silva, A. M. V., \& Almeida, L. P. (2017). Educação profissional: reflexões acerca da qualificação para o trabalho. In Anais, 13 CONPE - Congresso Nacional de Psicologia Escolar e Educacional pela Democratização da Educação (pp. 432-447). Salvador. São Paulo: Abrapee. Recuperado a partir de https:// abrapee.files.wordpress.com/2017/12/caderno-de-trabalhos-completos.pdf

Vigotski, L. S. (1991). A formação social da mente: o desenvolvimento dos processos psicológicos superiores. São Paulo: Martins Fontes.

Vigotski, L. S. (2001). A construção do pensamento e da linguagem. São Paulo: Martins Fontes.

Waldman, T. (2012). O acesso à educação escolar de imigrantes em São Paulo: a trajetória de um direito. (Dissertação de Mestrado), Faculdade de Direito, Universidade de São Paulo, São Paulo. 